\title{
TRIBUTAÇÃO DE ICMS SOBRE A PRESTAÇÃO DE SERVIÇO DE COMUNICAÇÃO DE CESSÃO DE CAPACIDADE ESPACIAL DE SATÉLITE / TAXATION OF ICMS ON THE PROVISION OF SERVICE OF COMMUNICATION OF
}

\section{ASSIGNMENT OF SPACE SATELLITE CAPACITY}

Mauricio Jorge Pereira da Mota $^{1}$

RESUMO: Neste artigo procuramos analisar a incidência do ICMS sobre a cessão de capacidade espacial de satélite, discutindo se a operação que as empresas proprietárias de satélites querem apresentar no momento da tributação como locação, é de fato uma locação, não tributável, ou, ao revés, é intrinsecamente, um serviço de comunicação que é prestado pelas empresas operadoras aos seus clientes através de seus satélites.

Palavras-chave: Satélites - Tributação - Cessão de capacidade espacial de satélites ICMS - Locação.

\begin{abstract}
In this paper we analyze the impact of the ICMS on the assignment of space satellite capacity, arguing that if the operation proprietary satellite companies want to present at the time of taxation as location, is in fact a lease, not taxable, or, in reverse, is inherently a communication service that is provided by the operating companies to their customers through their satellites.
\end{abstract}

KEYWORDS: Satellites - Taxation - Assignment of space satellite capacity - ICMS - Rental.

\footnotetext{
${ }^{1}$ Professor Adjunto da Faculdade de Direito da Universidade do Estado do Rio de Janeiro - UERJ. Procurador do Estado do Rio de Janeiro. Doutor em Direito Civil pela Universidade do Estado do Rio de Janeiro - UERJ.
} 


\section{INTRODUÇÃO}

Uma questão que vem sendo exaustivamente debatida em tempos recentes em direito tributário estadual em diversos Estados da federação se refere à incidência do ICMS sobre a prestação de serviço de comunicação de cessão de capacidade espacial de satélite.

Especificamente o problema gravita em torno da qualificação jurídica dos denominados contratos de cessão de capacidade espacial de satélite. Vários são os questionamentos nessa matéria: (a) quais os requisitos essenciais para a caracterização, no direito brasileiro, de um contrato de locação, especialmente de coisa móvel? (b) a atividade das empresas que se dedicam à chamada cessão de capacidade espacial de satélite pode ser considerada de locação? (c) em não sendo de locação as relações firmadas entre essas empresas e seus clientes, qual seria a classificação do contrato? Qual seria a natureza da obrigação assumida? (d) é correto dizer que a relação contratual entre essas empresas e seus clientes é de prestação de serviços de comunicação?

O presente artigo pretende dar uma resposta a essas indagações tão importantes para a correta tributação ou não de ICMS dessas atividades, por parte dos diversos fiscos estaduais. Para tanto o artigo examinará, sucessivamente, a distinção entre locação e prestação de serviço no direito brasileiro, a qualificação dos contratos celebrados entre essas empresas e seus clientes e, concluindo, definirá as proposições básicas da matéria no que concerne à tributação de ICMS.

\section{A TRIBUTAÇÃO DE ICMS NA MATÉRIA E SEUS FUNDAMENTOS}

1. A distinção entre locação e prestação de serviço no Direito brasileiro

A locação consiste em um contrato bilateral pelo qual alguém se obriga a ceder a outrem, por tempo determinado, o uso e gozo de coisa não fungível, mediante certa retribuição (CC, art. 565). A obrigação de conceder ao locatário o uso da coisa durante o tempo da locação é constitutiva dessa figura contratual. Identifica-se assim, ontologicamente, na figura contratual da locação de bens móveis, a presença de uma típica obrigação de dar, fundada na cessão de coisa não fungível.

Na prestação de serviço, ao revés, é o contrato bilateral no qual alguém se obriga a 
realizar uma atividade em serviço ou interesse de outrem. É o contrato onde são prometidas prestações de serviço de qualquer classe em troca de um preço ou remuneração (CC, art. 594). O que promete serviço, ou trabalho, deve a atividade mesma. Não há que se confundir: quem trabalha para quem contratou o serviço promete a atividade e não o resultado. $O$ tomador do serviço suporta o risco do contrato. No contrato de prestação de serviço, inclusive no contrato de trabalho, o tempo é elemento primordial, não o resultado da atividade. A figura da prestação de serviço se constitui, ao contrário da locação, em uma típica obrigação de fazer.

Importante também é a distinção da natureza da obrigação do locador e do prestador de serviço. Na locação, o locador é obrigado a entregar ao locatário a coisa em estado de servir ao uso a que se destina (CC, art. 566), ou seja, o locador deve colocar o locatário em situação de fazer da coisa o uso ordinário ou o uso determinado no contrato. Verificado isso, é incumbência do locatário, por seus meios, levar ou não a cabo o dito uso. Ao locador basta proporcionar ao locatário a possibilidade de "fazer uso" da coisa, para servir para aquilo a que ela se destina ${ }^{2}$. O prestador de serviço, ao revés, deve realizar a atividade no inteiro interesse do tomador do serviço, assegurar a utilidade, usando do melhor dos seus esforços e da sua aptidão para a consecução do desiderato contratual.

Assim, outro elemento fundamental que separa a locação da prestação de serviços é o valor do elemento trabalho do locador e do prestador do serviço. Esse elemento, na locação, do mesmo modo que ocorre em outros contratos, tem o caráter de uma prestação acessória, enquanto que na prestação de serviço constitui a prestação fundamental.

$\mathrm{Na}$ locação o locador tem que assegurar ao locatário a possibilidade de gozar a coisa arrendada e com isso termina toda a sua prestação, enquanto que na prestação de serviço o prestador de serviço deve prestar a própria atividade para procurar a utilidade que o tomador de serviço tem direito de obter. Se se detém a atividade do prestador de serviços, toda a utilidade desaparece, e o tomador do serviço só poderia obter proveito do que até então houvesse sido executado ${ }^{3}$.

Importa para a correta qualificação do contrato a função do produtor da utilidade. Basta se pensar no contrato de fornecimento de energia elétrica. No fornecimento de energia elétrica, o

\footnotetext{
2 LARENZ, Karl. Derecho de obligaciones. Tomo II. Madri: Revista de Derecho Privado, 1958, p. 199.

${ }^{3}$ FUBINI, Riccardo. El contrato de arrendamiento de cosas. Parte general. Madri: Revista de Derecho Privado, 1930, p. $16 / 17$.
} 
gozo do usuário não existe sem o esforço contínuo do arrendador na subministração da energia. Sem o labor do arrendador, que tem lugar de mil maneiras, todas muito complexas, na organização industrial, não é materialmente possível uma produção determinada de energia elétrica e seu fornecimento ao consumidor. Dessa maneira, faltando ao arrendatário a possibilidade de gozar em virtude da só natureza da coisa arrendada, e com independência do esforço de outras pessoas, não

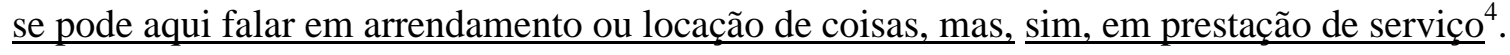

De outro lado, falando o Código na locação em entrega da coisa (CC, art. 566, I) e em garantia pelo locador do uso pacífico da coisa (CC, art. 566, II) não há que se imaginar nessa posse sobre coisa alheia a existência de uma posse meramente espiritual, (como é possível no direito integral sobre coisa própria, o direito de propriedade) sem apropriação da direção da coisa, porque não há na locação posse sem poder de direção do arrendatário sobre o uso e gozo da coisa, ainda que imaterial, porque isso desnaturaria o conceito civilístico de posse.

Não existindo esse momento de afirmação da senhoria do locatário, da direção por este da coisa alheia do locador, mas mera prestação da atividade do prestador de serviço ao arrendador do serviço, no interesse deste, posse não há e, assim, não se considera que a coisa foi de qualquer modo entregue como exige o dispositivo legal.

Na locação o locatário está obrigado, uma vez extinta a locação a devolver a coisa ao locador, no estado em que a recebeu (CC, art. 569, IV). A obrigação de devolver a coisa corresponde à fase de liquidação do contrato ${ }^{5}$. Na prestação de serviço não há qualquer dever de restituição ao final do contrato porque serviço, senso largo, é qualquer prestação de fazer, ou, de atividade no interesse de outrem ${ }^{6}$. A realização do serviço ou a prestação da atividade se consubstancia no próprio fazer, que é instantâneo e se tem por acabado logo após a sua consecução, ficando assim sua utilidade pertencendo a quem o pagou, nada havendo que restituir.

Por fim, o locatário que realiza benfeitorias necessárias tem o direito de retenção do bem locado para satisfazer sua pretensão de indenização (CC, art. 578). Isso para que seja eficaz o desiderato do direito de retenção, que é o pagamento dos valores das benfeitorias. Na prestação de

\footnotetext{
${ }^{4}$ FUBINI, Riccardo. El contrato de arrendamiento de cosas. Parte general. Madri: Revista de Derecho Privado, 1930, p. 20/21.

${ }^{5}$ LARENZ, Karl. Derecho de obligaciones. Tomo II. Madri: Revista de Derecho Privado, 1958, p. 206.

6 MIRANDA, Francisco Cavalcanti Pontes de. Tratado de Direito privado. Tomo 47. Campinas: Bookseller, 2006, § $5.038,1$.
} 
serviço a atividade é prestada no interesse do tomador do serviço e sob o próprio risco dele. Assim, não há direito à retenção de nada porque não há objeto específico ao qual a coisa seja vinculada.

2. A qualificação dos contratos firmados entre as empresas que têm como atividade a cessão de capacidade espacial de satélites e seus clientes

\subsection{Análise estrutural dos contratos}

2.1.1. A ausência dos elementos categoriais essenciais ou inderrogáveis do contrato de locação

$\mathrm{Na}$ análise da estrutura dos negócios jurídicos assumem relevo os elementos essenciais ou os essentialia negotti. São elementos essenciais gerais aqueles vinculados à própria existência do negócio jurídico. Normalmente são referidos como agente, objeto e forma, nos moldes do disposto no art. 104 do Código Civil ${ }^{7}$. Sem quaisquer dos elementos gerais não existe negócio jurídico. A eles serão acrescidos os elementos próprios de cada categoria, isto é, os elementos categoriais. Esses elementos não resultam de vontade das partes, mas, sim, da ordem jurídica, isto é, da lei e do que, em torno desta, a doutrina e a jurisprudência constroem (exemplos: compra e venda, locação, doação, depósito, comodato, mútuo).

Existem duas espécies de elementos categoriais: essenciais ou inderrogáveis e naturais ou derrogáveis. Os primeiros definem cada categoria de negócio e, portanto, caracterizam sua essência (exemplos: consenso sobre a coisa e o preço, na compra e venda; a manifestação do animus donandi e o acordo sobre a transmissão de bens ou vantagens, na doação). Os naturais podem ser afastados pela vontade das partes, sem que, por isso, o negócio mude de tipo (exemplos: responsabilidade pela evicção, na compra e venda).

Na locação são elementos categoriais inderrogáveis a obrigação de conceder ao locatário o uso e gozo da coisa não fungível durante o tempo da locação, mediante certa retribuição, para que este se sirva dela para o uso a que ela se destina. Como bem diz Karl Larenz,

\footnotetext{
7 Antonio Junqueira de Azevedo subdivide os elementos essenciais gerais em intrínsecos (ou constitutivos) e extrínsecos. Estariam entre os primeiros a forma, o objeto e as circunstâncias negociais ("quid... que faz com que uma manifestação de vontade seja vista socialmente como destinada à produção de efeitos jurídicos), e entre os segundos o agente, o lugar e o tempo (AZEVEDO, Antonio Junqueira de. Negócio jurídico: existência, validade e eficácia 4. ed. São Paulo: Saraiva, 2002, p. 32-33).
} 
caracterizando o elemento categorial inderrogável da locação: "a obrigação de conceder ao locatário o uso da coisa durante o tempo da locação é constitutiva dessa figura contratual. Não pode, portanto, faltar sem que o contrato perca o seu caráter de arrendamento de uso" ${ }^{\text {. }}$.

Deste modo, em primeiro lugar, sem a dação da coisa, a entrega da coisa alugada não há locação. Em segundo lugar, sem o uso e gozo da coisa, não há locação, ou seja, faltando ao locatário a possibilidade de gozar em virtude da só natureza da coisa arrendada, e com independência do esforço de outras pessoas, não há que se falar em locação. Em terceiro lugar, sendo elemento categorial inderrogável do contrato a entrega de coisa não fungível, não há locação se existir a fungibilidade da prestação. Em quarto lugar, pressupondo a locação a entrega da coisa para que o locatário se sirva dela para o uso a que se destina, não há locação sem poder de direção do locatário sobre o uso e gozo da coisa. Em quinto lugar, sendo elemento categorial inderrogável do contrato a entrega da coisa e seu uso e gozo restrito ao tempo da locação, a coisa deve ser restituída e, portanto, não há locação sem dever de restituição da coisa infungível. Por fim, da obrigação do locatário de servir-se da coisa alugada para o uso a que ela se destina, decorre seu dever de tratá-la com o mesmo cuidado como se sua fosse, realizando, portanto, obrigatoriamente, as benfeitorias necessárias na coisa, e, assim, podendo reter a coisa até ser ressarcido. Não há então, em princípio $^{9}$, que se falar em locação sem a possibilidade fática ou jurídica de reter a coisa locada. Pois bem. Examinando as relações jurídicas decorrentes dos contratos de cessão de capacidade espacial de satélites, verifica-se: 1 . esses contratos não prevêem a entrega de qualquer coisa aos clientes das empresas que têm como atividade a cessão de capacidade espacial de satélites; 2. o uso e gozo da utilidade proveniente dos contratos para os clientes das empresas que têm como atividade a cessão de capacidade espacial de satélites não decorre da só natureza da coisa dita cedida, a "capacidade espacial de satélite" e nem pode ser realizado com independência, sem pressupor o esforço contínuo, diuturno e permanente dessas empresas; 3. a coisa, o provimento de capacidade espacial, que as empresas que têm como atividade a cessão de capacidade espacial de satélites sustentam entregar não é infungível; 4. não há poder de direção dos clientes das empresas que têm como atividade a cessão de capacidade espacial de satélites sobre o uso e gozo da coisa dita locada, que permanece o tempo todo sob o mando e controle dessas empresas; 5. não há dever

\footnotetext{
${ }^{8}$ LARENZ, Karl. Derecho de obligaciones. Tomo II. Madri: Revista de Derecho Privado, 1958, p. 199.

${ }^{9}$ Esse direito de retenção, sendo uma decorrência natural da natureza da avença, pode ser afastado, mas somente por vontade expressa das partes.
}

Revista Quaestio luris, vol.04, no01. ISSN 1516-0351 p.623-654 628 
de restituição dos clientes das empresas que têm como atividade a cessão de capacidade espacial de satélites de qualquer coisa às empresas ditas locadoras; 6. os clientes das empresas que têm como atividade a cessão de capacidade espacial de satélites não tem possibilidade fática ou jurídica de reter a coisa locada. Especifiquemos tais considerações.

\subsubsection{Não há cessão ou entrega de coisa}

No contrato de locação a obrigação principal do locador é a de transmissão temporal da posse de objeto para que o locatário tenha o uso e/ou fruição. Nessa obrigação estão incluídos o dever de entregar ao locatário a coisa alugada, com suas pertenças, em estado de servir ao uso a que se destina, e o dever de mantê-la nesse estado, pelo tempo do contrato (art. 566, I, CC).

Não há entrega de bem nos contratos firmados entre as empresas que têm como atividade a cessão de capacidade espacial de satélites e seus clientes. Alocar, consoante o Dicionário Houaiss é "colocar algo em um ponto determinado, destinar a um fim específico". Temos assim uma atividade, uma obrigação de fazer, e não uma entrega, uma obrigação de dar.

$\mathrm{O}$ art. $9^{\circ}$ do Anexo à Resolução ${ }^{\circ} .220$, de 5 de abril de 2000 - Regulamento sobre o Direito de Exploração de Satélite para Transporte de Sinais de Telecomunicações é bem claro ao dispor que a dita "cessão" constitui uma atividade, o provimento de capacidade espacial, oferecimento de recursos, uma obrigação de fazer e não uma obrigação de entrega, de dar alguma coisa. Verifique-se que, consoante a regulamentação da lei, a prestadora contrata provimento de capacidade espacial (item X), ou seja, oferecimento de recursos de órbita e espectro radioelétrico (item XI) atividade de fazer, não obrigação de dar. Segmento espacial (item XVIII), na definição legal, é o satélite, e este remanesce sempre com as empresas que têm como atividade a cessão de capacidade espacial de satélites, em sua posse direta e indireta, durante todo o tempo do contrato.

Não há entrega de coisa incorpórea (a dita atribuição de órbita e freqüências) porque os clientes não passam a controlar, gerir os satélites e, mais do que isso, o só uso e gozo da coisa (a atribuição de órbita e de freqüências) consoante a sua natureza, por si só nada possibilita, sem a atividade da operadora do satélite.

No arrendamento de coisas o arrendador tem que assegurar ao arrendatário a 
possibilidade de gozar a coisa arrendada e com isso termina toda a sua prestação, enquanto que no arrendamento de serviços o arrendador deve prestar a própria atividade para procurar a utilidade que o arrendatário tem direito de obter. Se se detém a atividade do arrendador de serviços, toda a utilidade desaparece, e o arrendatário só poderia obter proveito do que até então houvesse sido executado ${ }^{10}$.

Aqui a atividade da operadora do satélite, sua prestação de serviço, domina toda a relação e a dita atribuição de órbita e freqüências nada mais é do que a atividade-meio, a condição que possibilita o fornecimento do serviço. A relação em questão tem o seu cerne, a sua utilitatis causa, na transmissão via satélite dos sinais de comunicações. Nessa transmissão, o que importa para as partes, e foi por isso que elas contrataram, é o transporte dos sinais. Para a comunicação, para o transporte de sinais, é necessário o uso da coisa, mas isso não qualifica o contrato como locação porque na locação tal uso da coisa é o fim único do contrato, e, no transporte ou transmissão de sinais de comunicação, é só o meio, com o qual o explorador da atividade pode alcançar o fim contratual a que se destina sua atividade (transmitir comunicação).

Como bem esclarece Riccardo Fubini, falando de transporte em geral, mas também aplicável ao transporte de sinais ou transmissão de comunicação ${ }^{11}$ :

"a atividade que o transportador se obriga a empregar para que o transporte se realize,
constitui o elemento essencial desse contrato; por isso, enquanto que no arrendamento de
coisas o vendedor se obriga só a conceder ao arrendatário o gozo da utilidade das coisas, o
transportador se obriga a transportar.
Não poderá falar-se de arrendamento, senão unicamente de transporte, não obstante as
expressões usadas pelas partes, nas hipóteses em que uma pessoa se obrigue a facilitar à
outra um determinado percurso em automóvel, coche etc.. Claro está que nesses casos a

${ }^{10}$ FUBINI, Riccardo. El contrato de arrendamiento de cosas. Parte general. Madri: Revista de Derecho Privado, 1930, p. $16 / 17$.

${ }^{11} \mathrm{O}$ que na realidade ocorre, nas atividades contratadas entre as empresas que têm como atividade a cessão de capacidade espacial de satélites e seus clientes é a alocação de uma porta de um satélite para transmitir sinais às estações terrestres habilitadas dos usuários, monitorando de forma permanente a recepção destes sinais, avaliando suas condições de fornecimento dos equipamentos, verificando a ocorrência de interferência ou outras interrupções que possam vir a causar ao serviço. É inequívoco, conseqüentemente, que os serviços prestados por essas empresas caracterizam um serviço de comunicação e, em sendo assim, sobre eles incide o ICMS, até porque, deve ficar claro, que o ICMS não incide sobre os serviços de telecomunicações (espécie), mas sim sobre serviços de comunicação (gênero). Assim dispõe o art. $3^{\circ}$, inciso XI da Lei $n^{\circ} 2.657 / 96$, in verbis: Art. $3^{\circ}$ - O fato gerador ocorrerá: XI - na prestação onerosa de serviços de comunicação feito por qualquer modo, inclusive a geração, a emissão, a recepção, a transmissão, a retransmissão, a repetição, e a ampliação de comunicação de qualquer natureza (grifos nossos). A Lei 2.657/96, se adequa plenamente a Constituição Federal e a Lei Complementar 87/96, a primeira quando ela confere competência exclusiva a Lei Complementar para em relação aos impostos nela discriminados estabelecer a definição dos respectivos fatos geradores (art. 186) e com a Lei Complementar nº 87/96, quando ela determina a incidência do ICMS sobre as prestações onerosas de serviços de comunicação por qualquer meio (art. $2^{\circ}$, inc. II). 
atividade do transportador é essencial. Ele é que tem que preocupar-se com o meio de transporte e sua obrigação não se contrai com a concessão de uso da coisa por um certo tempo, mas sim realizando um percurso determinado ${ }^{12}$.

Não há assim, entrega operacional seja da coisa, seja do seu uso (a dita atribuição das órbita e de frequiências) porque as empresas que têm como atividade a cessão de capacidade espacial de satélites se asseguram o pleno controle dos satélites, da frequência utilizada e demais características técnicas. Deste modo, nesses contratos não há entrega de qualquer coisa aos clientes, seja a operação do satélite em si, seja a capacidade espacial. Como explicado, os contratos em referência têm como objeto a alocação de provimento de capacidade (uma obrigação de fazer), objeto de prestação de serviço (prestação onerosa de serviço de comunicação feito de qualquer modo) e não uso e gozo da própria coisa por sua natureza (obrigação de dar) porque a dita coisa (a atribuição de órbita e de frequiências) nada é sem a atividade diuturna, prestada em regime integral, 24 (vinte e quatro) horas por dia, todos os dias do mês, por essas empresas que têm como atividade a cessão de capacidade espacial de satélites.

2.1.1.2 O uso e gozo da utilidade não decorre da só natureza da coisa cedida

Assevera Serpa Lopes que toda a importância da obrigação de entrega da coisa, dessa prestação, assenta em ser ela um meio para o cumprimento daquilo que constitui a essência do contrato de locação - o uso e gozo da coisa locada - os quais não se tornam efetivos sem a entrega daquilo que lhes forma o objeto ${ }^{13}$. É elemento categorial inderrogável do contrato de locação assim, o uso e gozo da utilidade que decorre da só natureza da coisa cedida. Por isso a lei fala em entregar ao locatário a coisa em estado de servir ao uso a que se destina (CC, art. 566) e a mantê-la nesse estado, ou seja, o locador deve colocar o locatário em situação de fazer da coisa o uso ordinário ou determinado no contrato (CC, art. 567).

O uso e gozo da coisa pelo locatário se faz em decorrência da só natureza da coisa cedida, servindo a coisa para o fim a que se destina. Pois bem. Nos contratos firmados entre as empresas que têm como atividade a cessão de capacidade espacial de satélites e os seus clientes, não é a coisa em si (a atribuição de órbita e de freqüências) em sua natureza que permite a utilidade

\footnotetext{
12 FUBINI, Riccardo. El contrato de arrendamiento de cosas. Parte General. Madri: Revista de Derecho Privado, 1930, p. $45 / 46$.

${ }^{13}$ LOPES, Miguel Maria de Serpa. Locação de coisas. Rio de Janeiro: Freitas Bastos, 1956, p. 45.
} 
(o uso e gozo da transmissão de sinais) mas, sim, a atividade diuturna dessas empresas prestada em regime integral, 24 (vinte e quatro) horas por dia, todos os dias do mês.

Senão vejamos. Qual a especificidade da coisa de que estamos falando? A operação em comento resume-se à seguinte fórmula: uma empresa $\mathrm{A}$, operadora de um satélite, concede a uma empresa B certa capacidade de potencial de transmissão do instrumento que se encontra em órbita, expressa em megahertz, através da instalação de "transponders" ${ }^{14}$ com a constante manutenção desse meio de trânsito de informações. Fácil de se notar, pela só descrição da coisa e da operação, que esta não é apta para realizar por si só, por sua natureza, o uso e gozo da utilidade pretendida pelas partes, sem a atividade do pretenso locador, as empresas que têm como atividade a cessão de capacidade espacial de satélites. Logo, não há locação, mas sim, prestação de serviço da operadora do satélite para as empresas, seus clientes, para que a utilidade pretendida pelas partes (a comunicação) seja possível.

Dessa maneira, faltando aos clientes dessas empresas a possibilidade de gozar em virtude da só natureza da coisa arrendada (o transponder em uso no satélite), e com independência do esforço dessas empresas, não se pode aqui falar em locação, mas, sim, em prestação de serviço.

2.1.1.3 A coisa, o provimento de capacidade espacial, que as empresas que têm como atividade a cessão de capacidade espacial de satélites sustentam entregar não é infungível

Heleno Taveira Torres assim conceitua a denominada locação de capacidade espacial:

\begin{abstract}
Decididamente, no domínio da capacidade de satélite, não cabe falar de "cessão", posto não se tratar de tecnologia; nem tampouco há serviço, por ausência de obrigação de "fazer" que se constitua em utilidade em favor do utente. Tem-se, na espécie, hipótese de "uso", a título oneroso (do contrário ter-se-ia comodato)", como obrigação de "dar" bem não-fungível, o que configura claramente o caso de locação, e não mais do que isso, no provimento de capacidade espacial. Na análise do direito estrangeiro sobre o tratamento aplicável a essa matéria, igualmente vê-se referência apenas ao contrato de "locação", o
\end{abstract}

\footnotetext{
${ }^{14}$ Transponder (abreviação de transmitter-responder) é um dispositivo complementar de automação e cujo objetivo é receber, amplificar e retransmitir um sinal com frequência diferente ou transmitir um sinal em uma frequência diferente ou transmitir de uma fonte uma mensagem pré-determinada em resposta a uma outra pré-definida de outra fonte. Esses equipamentos, no caso de operação de cessão de capacidade espacial, funcionam como o meio necessário para que a comunicação, entre o satélite e as estações terrestres se estabeleça
} 
que não poderia ser diferente, por tudo o que já dissemos acima, cujo estudo sobre suas peculiaridades impõe-se desde logo 15 .

Depois descreve que tal "obrigação de dar" nesse contrato consistiria em dar coisa não fungível, assim caracterizada:

Vê-se que o Código oferece como limite à locação de coisas que esta se faça a título de "uso e gozo" e que a "não-fungibilidade" da coisa ou do serviço seja requisito para sua adequada qualificação. Assim, bens fungíveis não podem ser locados. Ora, na medida em que "são fungíveis os móveis que podem substituir-se por outros da mesma espécie, qualidade e quantidade" (art. 85, do Código Civil), a capacidade satelital queda-se excluída de tal qualificação, pois as atribuições de frequência e órbita, por serem previamente delimitadas e não substituíveis, após o competente registro, não são modalidades de bens fungíveis, tal como designado pelo Código, cabendo, assim, seu uso mediante "locação" ${ }^{16}$ (grifos nossos).

15 TORRES, Heleno Taveira. Direito tributário das telecomunicações e satélites. São Paulo: Quartier Latin, 2007 , p. 280.

16 TORRES, Heleno Taveira. Direito tributário das telecomunicações e satélites. São Paulo: Quartier Latin, 2007, p. $274 / 275$. 
A coisa que se entrega, portanto, no dizer do autor, é o uso e gozo do potencial de transmissão de determinadas atribuições de frequência e órbita, para transmissão de sinais através dos transponders dos satélites das empresas que têm como atividade a cessão de capacidade espacial de satélites.

Ora, a locação trata somente de uso e gozo da coisa por período determinado, devendo o locatário restituir a coisa, finda a locação, no estado em que a recebeu, salvo as deteriorações naturais ao uso regular (CC, art. 569, IV). Esta obrigação constitui um dever de prestação independente. A devolução da coisa não representa uma contraprestação (ou uma parte desta) à prestação do locador, se achando fora da relação sinalagmática. A obrigação de devolver a coisa corresponde à fase de liquidação do contrato ${ }^{17}$. Assim, devendo o locatário devolver a coisa locada sem alteração, no estado em que a recebeu, não se admite a locação de coisas fungíveis. Resta induvidoso que o bem em questão, uso e gozo do potencial de transmissão de determinadas atribuições de frequência e órbita, é fungível, uma vez que é um bem móvel que pode ser substituído por outro de mesma espécie, qualidade e quantidade, como atestam os contratos padrão na matéria.

Portanto, se as empresas que têm como atividade a cessão de capacidade espacial de satélites podem, a qualquer tempo, a seu exclusivo critério, alterar as designações de satélite, segmentos de satélites e suas faixas de frequência de operação e polarização para a operação de cessão, a coisa que ela alega ceder a seus clientes é fungível, nos termos do disposto no art. 85 do Código Civil. Sendo o bem em questão fungível, não há que se falar em locação.

2.1.1.4 Não há poder de direção dos clientes das empresas que têm como atividade a cessão de capacidade espacial de satélites sobre o uso e gozo da coisa locada

Estabelecendo o Código Civil na locação a entrega da coisa (CC, art. 566, I) e

\footnotetext{
${ }^{17}$ Derecho de obligaciones. Tomo II. Madri: Revista de Derecho Privado, 1958, p. 206.
} 
disciplinando a garantia pelo locador do uso pacífico da coisa (CC, art. 566, II) não há que se imaginar que essa posse sobre coisa alheia na locação possa ser uma posse sem poder de direção do arrendatário sobre o uso e gozo da coisa, ainda que imaterial, porque isso desnaturaria o conceito civilístico de posse.

Alega Heleno Taveira Torres em seu livro que os clientes das empresas que têm como atividade a cessão de capacidade espacial de satélites exercem o poder de direção sobre a coisa que decorre do uso e gozo da coisa, inclusive podendo fazer uso das ações possessórias:

\begin{abstract}
Com a posse da capacidade satelital locada, o locatário passa a ter os direitos de garantia contra interferências, podendo exigir proteção em favor dos sigilos de dados e todas as demais garantias aplicáveis. As ações possessórias podem nascer-lhe. Segundo Pontes, verifica-se sempre um efeito possessório no contrato de locação. E assim, "quer no tocante à proteção possessória em relação com o terceiro, quer no tocante à proteção com relação ao próprio locador, o locatário é possuidor". Arremata-se, pois, a dizer que essas modalidades em nada se aproximam de prestações de serviços ou similares ${ }^{18}$ (grifos nossos).
\end{abstract}

A posse, no entanto, na realidade, consiste em uma manifestação exterior da apropriação econômica da coisa, isto é, um estado fático tal que revela o senhorio de fato da coisa, aquele que a tem sob sua dependência e que a faz servir para a satisfação de suas necessidades econômicas. $\mathrm{O}$ animus aplicado ao corpus será, por conseguinte, a vontade de realizar a apropriação econômica da coisa, a vontade de agir como senhor de fato da coisa ${ }^{19}$. É preciso remontar à tomada da posse e ver em que circunstâncias e em que condições jurídicas ela teve lugar: é preciso que em um momento dado aquele que se pretende possuidor tenha afirmado sua senhoria sobre a coisa. Vejamos se há relação possessória nos contratos que estamos tratando.

Não há nenhuma senhoria ou poder de direção dos clientes das empresas que têm como atividade a cessão de capacidade espacial de satélites sobre a coisa, seja da coisa em si, seja do seu uso (a dita atribuição das órbitas e de frequiências) porque essas empresas se asseguram o pleno controle dos satélites, de sua posição orbital, da frequência utilizada e demais características

\footnotetext{
18 TORRES, Heleno Taveira. Direito tributário das telecomunicações e satélites. São Paulo: Quartier Latin, 2007 , p. 279.

${ }^{19}$ SALEILLES, Raymond. Étude sur les eléments constitutifs de la possession. Dijon : Imprimerie Darantie, 1894, p. 183
}

Revista Quaestio luris, vol.04, no01. ISSN 1516-0351 p.623-654 635 
técnicas. Além disso, tal controle é mantido diuturnamente com exclusividade por essas empresas, 24 (vinte e quatro) horas por dia, todos os dias do mês, evidenciando a ausência de poder de direção dos clientes dessas empresas sobre a coisa.

Além disso é evidente que os clientes das empresas que têm como atividade a cessão de capacidade espacial de satélites, em caso de litígio com essas operadoras de satélite, não poderão fazer uso de quaisquer ações possessórias. Primeiro, porque não tem posse, remanescendo os satélites na posse direta e indireta dessas empresas a $36.000 \mathrm{~km}$ de distância da Terra. Portanto, em todas as cláusulas primordiais do contrato se evidencia a posse direta e indireta das empresas que têm como atividade a cessão de capacidade espacial de satélites sobre os bens e direitos em tela e sua plena senhoria e poder de direção da coisa, o que desnatura a idéia de locação.

\subsubsection{Não há dever de restituição}

Na locação o arrendatário está obrigado, uma vez extinta a locação a devolver a coisa ao locador, no estado em que a recebeu (CC, art. 569, IV). Como já dito, esta obrigação constitui um dever de prestação independente. A devolução da coisa não representa uma contraprestação (ou uma parte desta) à prestação do locador, se achando fora da relação sinalagmática. A obrigação de devolver a coisa corresponde à fase de liquidação do contrato ${ }^{20}$.

Os contratos de locação ou cessão de provimento de capacidade espacial firmados pelas empresas que têm como atividade a cessão de capacidade espacial de satélites com seus clientes não prevêem qualquer restituição da coisa cedida. Por motivos óbvios. Não se trata de contratos de locação. Nada foi transferido no âmbito desses contratos. Os satélites, sua incorpórea possibilidade de provimento de capacidade espacial, tudo, permanece sob a direção e controle dessas empresas. A utilidade de que é suscetível a coisa nesse contrato (a comunicação, a transmissão de sinais) não é resultante da natureza da coisa (os transponders) [o uso a que se

\footnotetext{
${ }^{20}$ Derecho de obligaciones. Tomo II. Madri: Revista de Derecho Privado, 1958, p. 206.
} 
destina de que fala o art. 566, I, do Código Civil], mas sim, diz respeito a direitos correlativos, que só incidentalmente estão ligados à coisa. Não há porque falar da utilidade desta, senão unicamente de entidades patrimoniais, direitos correlativos, que estão fora da coisa e que derivam de uma série de elementos que emanam da pessoa que os criou. É a atividade dessas empresas, sua organização de todo o empreendimento que possibilita a comunicação, e ela presta essa atividade no interesse de outrem, seus clientes, através de uma prestação de serviços. Não é a coisa a que dá vida a tal utilidade, senão que é unicamente ocasião dela, nem representa mais do que um dos elementos que podem influir sobre a entidade patrimonial. Indiscutível se considerar, portanto, que na cessão de direitos correlativos de uso e gozo de "provimento de capacidade espacial" que ocorrem por ocasião da coisa [através da coisa] não há mais do que uma prestação de serviço do prestador, ao tomador do serviço, seus clientes, no interesse destes.

Não há que se considerar tal cessão de direitos correlativos de uso e gozo senão como o que ela é, uma cessão especial de direitos correlativos ao bem das empresas que têm como atividade a cessão de capacidade espacial de satélites no interesse dos cessionários dos direitos correlativos, seus clientes. Sendo a prestação realizada no precípuo interesse dos clientes este é o motivo pelo qual, ao término do contrato, os ditos clientes levam com eles todos os benefícios e utilidades que ocorreram por ocasião ou através da coisa, não havendo que se falar em nenhum dever de restituição.

\subsubsection{Não há direito de retenção}

O direito de retenção por benfeitorias é um dos vários meios diretos de defesa que a lei, excepcionalmente, confere ao titular de um direito. Consiste na liberdade, deferida ao credor, de conservar a coisa além do momento que a deveria restituir, em garantia de um crédito que tenha contra o devedor e decorrente de despesas feitas ou perdas sofridas em razão da coisa. Na locação o locatário que realiza benfeitorias necessárias tem o direito de retenção do bem locado para satisfazer 
sua pretensão de indenização (CC, art. 578). Isso para que seja eficaz o desiderato do direito de retenção, que é o pagamento dos valores das benfeitorias.

Não há qualquer direito de retenção nos contratos firmados pelas empresas que têm como atividade a cessão de capacidade espacial de satélites com seus clientes. Não há para os clientes dessas empresas operadoras qualquer possibilidade fática de retenção seja dos satélites, dos transponders ou da capacidade espacial. Só através das empresas operadoras eles auferem a utilidade da coisa, o que demonstra aqui, uma vez mais, que não se trata de nenhuma locação.

A análise dos elementos essenciais do contrato, que se pauta pela verificação da presença de um rol de elementos reputados necessários e suficientes para o enquadramento do contrato concreto no tipo legal, não esgota a análise contratual. É preciso proceder a uma análise da função concretamente desempenhada pelo contrato em tela.

\subsection{Análise funcional dos contratos}

2.2.1. A base objetiva do contrato de provimento de capacidade espacial

A base objetiva do negócio jurídico é a "soma das circunstâncias e o estado geral de coisas cuja existência ou subsistência sejam objetivamente necessárias para que o contrato subsista, segundo o significado das intenções de ambos os contratantes, como regulação dotada de sentido" 21 . Ela visa garantir ao contrato a plena realização de sua finalidade prático-social, ou seja, visa preservar a utilidade do contrato, em si, e para ambos os contratantes.

Assim afirma Larenz desaparece a base objetiva do negócio jurídico "se a consecução da finalidade última de ambas as partes há resultado impossível, cada uma delas pode resolver o contrato, e só tem lugar a indenização de danos e prejuízos quando uma parte tiver

${ }^{21}$ LARENZ, Karl. Base del negocio juridico y cumplimiento de los contratos. Madrid: Revista de Derecho Privado, 1956, p. 225. 
produzido a transformação das circunstâncias por seus atos livres e, por conseguinte, deva responder por eles" ${ }^{22}$. Larenz desenvolve a idéia de que existe necessariamente um liame lógico e objetivo entre a base do negócio e o fim do contrato. O contrato é elaborado em determinados termos, para que possa gerar certos efeitos. Esses efeitos somente têm sentido quando são analisados a partir de seu suporte fático. Segundo Larenz, um contrato não pode subsistir como um negócio dotado de sentido quando a finalidade objetiva do contrato expressa em seu conteúdo, se torna inalcançável. Essa finalidade objetiva do contrato deduz-se da natureza do contrato ou de seu conteúdo expresso.

Vejamos então qual seja a finalidade prático-social, a utilidade, do denominado “contrato de provimento de capacidade espacial”. A finalidade prático-social do contrato é a comunicação. As partes do contrato querem possibilitar a comunicação. O contratante, o tomador do serviço, quer, por exemplo, a transmissão de uma partida de futebol jogada no exterior, por uma estação de TV. Sem o satélite, tal desiderato é impossível. O operador do satélite, por seu turno, quer que tal comunicação se realize e se realize através do meio por ele colocado à disposição para tal comunicação, o satélite. Por esse serviço, pretende receber uma retribuição, o preço. Essa é a base objetiva do negócio firmado entre as partes.

A apresentação desse contrato com o nomem iuris de "contrato de cessão de capacidade espacial" e sua conceituação jurídica como uma locação de bens, sendo um aluguel a denominação da receita auferida pelas empresas operadoras com o contrato, não condiz com a realidade, pois equivale a dizer que é possível locar capacidade espacial de emissão, recepção e transmissão, através de um meio de comunicação, sem possibilitar o acesso do usuário a tal meio. Seria desnaturar a base objetiva do negócio jurídico que é o efetivo negócio querido, efetuado e praticado pelas partes, o fim objetivo do contrato celebrado.

Como bem destaca Riccardo Fubini analisando o fim objetivo dos contratos de arrendamento de coisas e de arrendamento ou contrato de serviços o que realmente separa o arrendamento ou contrato de serviços do arrendamento de coisas é o valor do elemento trabalho,

\footnotetext{
${ }^{22}$ Base del negocio juridico y cumplimiento de los contratos. op. cit., p. 150.
} 
elemento que no arrendamento de coisas, do mesmo modo que ocorre em outros contratos, tem o caráter de uma prestação acessória, enquanto que no arrendamento de serviços constitui a prestação fundamental. Assim, este é o critério científico que deve ser utilizado para classificar essa convenção jurídica sob um novo nomem iuris, contrato de serviços.

O que na realidade ocorre aqui é a alocação de uma porta de um satélite para transmitir sinais às estações terrestres habilitadas dos usuários, monitorando de forma permanente a recepção destes sinais, avaliando suas condições de fornecimento dos equipamentos, verificando a ocorrência de interferência ou outras interrupções que possam vir a causar ao serviço. Não há assim, como se negar, que aquilo que o autor da demanda quer apresentar como locação, é intrinsecamente um serviço de comunicação que é prestado aos seus clientes através do satélite. Não pode o uso e gozo da coisa, o transponder, constituir a base objetiva do presente negócio jurídico porque a locação propriamente dita é um negócio jurídico autônomo, pelo qual o locador entrega a coisa locada para que o locatário lhe dê a utilização que lhe é própria, utilizando e gozando da coisa, sem qualquer condicionamento ou vinculação a outro tipo de negócio. Este é o fim contratual do negócio jurídico de locação. $\mathrm{Na}$ locação de um veículo, por exemplo, o locador o utiliza sem que haja outro negócio paralelo ou outra remuneração a ser paga, senão o preço do aluguel. Os clientes das empresas que têm como atividade a cessão de capacidade espacial de satélites não têm qualquer conhecimento técnico necessário à operação do satélite, nem se propõem a fazê-lo, por iniciativa própria, como se daria em uma locação.

A base do negócio jurídico avençado, sua finalidade prático-social, não pode ser outra senão a comunicação pretendida pelas partes, com transmissão dos sinais feita através do satélite, dirigido e operado com exclusividade pelas empresas operadoras. Então, deste modo, a atividade primordial dessas empresas, é possibilitar essa comunicação e, assim, seu negócio precípuo é a prestação de serviços de comunicação, sendo a parcela por ela denominada de locação, parte incindível da prestação do serviço de comunicação.

Quando o fim do contrato, a base objetiva do negócio jurídico, é a prestação do serviço, ele é o que define a qualificação do contrato. Assim, pode-se cogitar que a prestação de um serviço seja acompanhada do fornecimento temporário de um bem móvel. É o que se dá, por 
exemplo, quando são prestados serviços de organização de festas ou recepções em que o prestador do serviço fornece o equipamento de som e os móveis necessários à ocorrência do evento. Nesse caso o uso e gozo do equipamento de som e dos móveis são apenas atividades-meio não autônomas atreladas à prestação de serviço, nesse caso há um verdadeiro serviço-fim, sobre o preço do qual deverá incidir, sem dúvida alguma, a tributação.

Como se verifica nos contratos padrão de provimento de capacidade espacial as empresas operadoras operacionalizam e tornam possível permanentemente a comunicação de seus clientes. O fim do contrato não pode ser caracterizado como locação porque a locação objetiva transferir a posse direta de um bem para que o locatário extraia dele a utilidade que é própria da coisa. A utilidade de que é suscetível a coisa é, simplesmente, a resultante de sua natureza [o uso a que se destina de que fala o art. 566, I, do Código Civil]. Ora, no caso dos contratos das empresas que têm como atividade a cessão de capacidade espacial de satélites com seus clientes, a utilidade da coisa que permite a comunicação (os transponders) é nenhuma sem a atuação dessas empresas.

Trata-se aqui, induvidosamente, de prestação de serviço como o fim do contrato porque não se pode conceber a execução dos contratos celebrados entre essas empresas e seus clientes e a atribuição da utilidade ao tomador de serviço (os clientes) nem, por conseguinte, a consecução dos fins que este se havia proposto (a comunicação), sem a contínua colaboração do prestador de serviço (as empresas operadoras), que, com seu próprio esforço tem que produzir as vantagens prometidas. A atividade primordial das empresas operadoras é possibilitar essa comunicação e, assim, seu negócio precípuo é a prestação de serviços de comunicação, sendo a parcela por elas denominada de locação, parte incindível da prestação do serviço de comunicação.

2.2.2. A causa concreta do contrato de provimento de capacidade espacial

A causa do contrato deve ser compreendida como causa em concreto, o interesse

Revista Quaestio luris, vol.04, no01. ISSN 1516-0351 p.623-654 641 
social que o contrato singular pretende perseguir, um interesse portanto ainda econômicosocial, porém perseguido não por um tipo contratual pré-confeccionado, mas sim avaliado "no particular contexto de circunstâncias e finalidades e interesses no qual aquelas partes o programaram"23.

São características dessa causa do negócio jurídico: a) é concreta, porque se verifica em cada caso em particular; b) é variável, porque pode ser diferente em cada negócio concreto suposto; c) não é suficiente examiná-la em seu momento genético, é preciso também considerar a produção de seus efeitos ${ }^{24}$.

$\mathrm{Na}$ interpretação dos contratos, a causa em concreto é fundamental no processo de qualificação contratual na medida em que favorece a identificação e valorização das peculiaridades do contrato efetivamente firmado entre as partes. Trata-se do elemento que define o negócio, que lhe é próprio e único e que serve para o diferenciar de qualquer outro negócio, típico ou atípico. Assim, o intérprete, para qualificar o contrato, deve cotejar a causa do contrato concreto com a causa abstrata prevista no âmbito dos tipos, individualizando o dito contrato em seu perfil próprio no contexto negocial. Como bem assevera Maria Celina Bodin de Moraes:

\begin{abstract}
A função abstrata releva (...) porque dela se extrai o conteúdo mínimo do negócio, aqueles efeitos mínimos essenciais sem os quais não se pode, em concreto - ainda que assim se tenha idealizado -, ter aquele tipo, mas talvez um outro, ou mesmo nenhum. No exemplo da compra e venda, se falta o preço, de compra e venda não se tratará, mas, talvez, de doação. Já a função concreta diz respeito ao efetivo regulamento de interesses criado pelas partes e não se pode, a priori, estabelecer que efeitos são essenciais e quais não o são, naquele particular negócio. Para a qualificação do concreto negócio será necessário examinar cada particularidade do regulamento contratual porque uma cláusula aparentemente acessória pode ser, em concreto, o elemento individualizador da função daquele contrato. Supera-se, desta forma, a técnica da subsunção, da forçada inserção do fato na norma e da premissa menor na premissa maior, obtendo-se, como resultado, uma qualificação-interpretação mais compatível com a manifestação de vontade das partes ${ }^{25}$.
\end{abstract}

23 ROPPO, Vincenzo. Il contratto. Milano: Giuffrè, 2001, p. 364.

${ }^{24}$ LORENZETTI, Ricardo Luis. Tratado de los contratos. Parte General. Santa Fé: Rubinzal Culzoni Editores, 2004, p. $412 / 413$.

${ }^{25}$ MORAES, Maria Celina Bodin de. A causa dos contratos. in: Revista Trimestral de Direito Civil. Rio de Janeiro: PADMA, vol. 21, pp. 95-119, jan./mar. de 2005, p. 108.

Revista Quaestio luris, vol.04, no01. ISSN 1516-0351 p.623-654 642 
O Superior Tribunal de Justiça usualmente qualifica os contratos pela causa concreta. Por exemplo, analisando a discussão sobre a incidência da Cofins nos contratos de locação de espaços em shopping centers interpretou acertadamente que, embora tal contrato aparentemente se enquadre no tipo contratual da locação de bens, não passível de incidência da Cofins, a causa concreta do contrato é o plano estratégico, o mix rentável do negócio shopping center e sua devida retribuição de tal prestação por um aluguel percentual. Como esse chamado "aluguel percentual" é na realidade uma parte do faturamento da loja, sobre o qual já incide a Cofins, ele não pode ser novamente tributado para que não se configure um bis in idem.

Nesta linha de identificar a função concreta que o diferencia do modelo padrão, afirmou o voto da relatora que "o aspecto mais interessante do shopping center e que o distingue como contrato atípico é o propósito principal: relação associativa entre empreendedor e lojistas, que põem em prática um plano estratégico que mistura produtos e serviços, com vista a um fim comum: rentabilidade pela venda de mercadorias, da qual participam ambos". Assim, constatou-se que, no caso específico dos contratos relativos aos shopping centers, o mecanismo próprio de remuneração é o "aluguel percentual", o qual, por incluir parte do faturamento obtido pelo lojista nas suas próprias operações comerciais, já havia sofrido a incidência da Cofins e não poderia novamente ser tributado pela mesma Cofins ${ }^{26}$. Isso posto, analisemos a causa concreta do contrato de provimento de capacidade espacial.

Primeiro deve ser analisado o chamado programa contratual, o contexto de circunstâncias negociais e as finalidades e interesses no qual as partes, as empresas que têm como atividade a cessão de capacidade espacial de satélites e e seus clientes, programaram o dito contrato de provimento de capacidade espacial.

1) Inicialmente, verifiquemos a coerência do contrato com a realidade:

\footnotetext{
${ }^{26}$ Superior Tribunal de Justiça. Segunda Turma. REsp 972501 SP. Relatora: Ministra Eliana Calmon. Julgamento: 01/04/2008. Publicação: DJ 11/04/2008.
}

Revista Quaestio luris, vol.04, no01. ISSN 1516-0351 p.623-654 643 
a) As características do estabelecimento prestador: seus atos constitutivos, seus equipamentos, seus setores de atividades, sua propaganda e publicidade (exibição à sociedade, inclusive sítio de internet) etc.

As empresas operadoras, via de regra, descrevem em seus atos constitutivos que sua atividade não é a de locação de provimento de capacidade espacial, mas sim, a prestação de uma série de serviços de comunicação via satélite. E apresentam sua atividade como sendo a prestação de serviço de controle de satélites:

b) As características, os interesses ou as necessidades do tomador de serviços.

As empresas que têm como atividade a cessão de capacidade espacial de satélites se dizem fornecedoras de bens mediante locação, segundo contrato firmado, sem que, no entanto, o tomador dos bens (seus clientes) tenham meios para operar e utilizar tais bens (equipamentos) para obter o benefício desejado.

c) As características específicas do serviço, segundo o costume e a tradição, tanto da sociedade (geral) quanto da cultura de determinada empresa (específica).

Não se concebe socialmente que possa ser atividade das empresas que têm como atividade a cessão de capacidade espacial de satélites conceituada como tendo a natureza jurídica de uma locação de bens, remunerada por meio de aluguel porque isso não condiz com a realidade social, a natureza das coisas, pois equivale a dizer que é possível locar capacidade espacial de emissão, recepção e transmissão, através de um meio de comunicação, sem possibilitar o acesso do usuário a tal meio.

2) Depois, a indivisibilidade da obrigação em tela no contrato:

A obrigação pode ser divisível ou indivisível, segundo classifica o Código Civil. Esta classificação importa especialmente aos negócios jurídicos em que há pluralidade de credores ou de devedores. O Código Civil em seu art. 258 estabelece quando uma obrigação, contrariamente, é considerada indivisível: 
Art. 258. A obrigação é indivisível quando a prestação tem por objeto uma coisa ou um fato não suscetíveis de divisão, por sua natureza, por motivo de ordem econômica, ou dada a razão determinante do negócio jurídico.

O artigo 258 fala de "fato não suscetível de divisão", o que vale dizer que o Código Civil não estipula a indivisibilidade apenas para coisas, mas também para fatos, como uma prestação de serviço. Quando um fato "prestação de serviços" deve ser considerado indivisível? Quais os critérios suficientes para que se obtenha uma resposta clara a esta distinção entre o que é divisível e o que é indivisível? A característica de ser divisível ou indivisível é qualidade da obrigação que a norma conceitua e reconhece, de certa maneira, porque corresponde a uma característica real, quando a sua natureza a faz una e incindível.

Assim, não há como negar a indivisibilidade de um conjunto de obrigações contratuais nas situações em que o não atendimento de uma prestação frustra a totalidade do negócio ou, ainda, quando a insuficiência de uma das "sub-prestações" pode frustrar ou comprometer o resultado final, sendo a responsabilidade diretamente imputada ao prestador de serviço. Ainda que se formalizem manifestações de vontade separadas, envolvendo terceiros, o nexo que as une se mostra ao cliente de alguma maneira, porque a tranqüilidade deste na avença decorre da responsabilidade plena assumida pelo tomador quanto ao resultado final.

Claramente temos no "contrato de provimento de capacidade espacial" uma obrigação incindível, o contrato não pode se qualificar como locação porque pela só subprestação (o uso e gozo da coisa, o transponder, consoante a sua natureza) não se chega ao fim colimado para o contrato (a comunicação). O só uso e goza da coisa incorpórea (a atribuição de órbita e de freqüências realizada através do transponder) consoante a sua natureza, por si só nada possibilita, sem a atividade da operadora do satélite. É uma atividade (prestação dos serviços de comunicação) aquilo que é o escopo contratual das partes nos contratos e só podendo o serviço ser realizado por meio da coisa (atividade-meio, condição para a prestação do serviço) a obrigação é incindível em razão do negócio concreto realizado, nos termos do art. 258 do Código Civil.

Por fim, analisa-se a causa em concreto, que fundada no programa contratual do 
negócio antes descrito, arremata-se na complexidade contratual do dito contrato de provimento de capacidade espacial.

O Supremo Tribunal Federal, fundado na percuciente lição de Orlando Gomes, analisando os contratos mistos, já consagrou há muito tempo que o que qualifica o contrato é sua causa concreta, ou seja, o fim objetivo almejado pelas partes:

\begin{abstract}
O que caracteriza o contrato misto (ou complexo) é a coexistência de obrigações pertinentes a tipos diferentes de contratos, enlaçadas pelo caráter unitário da operação econômica, cujo resultado elas asseguram. Ele se distingue da união de contratos, que se caracteriza pela coexistência, num mesmo instrumento, de tais obrigações simplesmente justapostas, sem a amálgama da unidade econômica aludida. No caso de união de contratos, pode ser anulado ou rescindido um deles, sem prejuízo dos outros, enquanto que, em se tratando de contrato misto, o grau de síntese alcançado torna inseparáveis as partes ou elementos do negócio. Outrossim, cumpre-nos advertir que as regras principais a serem observadas, em relação ao contrato misto, são estas: 'a) cada contrato se rege pela norma de seu tipo; b) mas tais normas deixam de ser incidentes quando se chocarem com o resultado que elas visam assegurar (STF, $1^{\mathrm{a}}$ T, RE 79562-SP, rel. Min. Rodrigues Alckmin, v.u.,10.01.76, RTJ 77/884).
\end{abstract}

Vejamos então o nosso objeto, o contrato de provimento de capacidade espacial. A causa concreta do contrato de provimento de capacidade espacial, o interesse social que o contrato singular pretende perseguir, é a comunicação. As partes do contrato querem possibilitar a comunicação. Como antes dito, o contratante, o tomador do serviço quer, por exemplo, a transmissão de uma partida de futebol jogada no exterior, por uma estação de TV. Sem o satélite, tal desiderato é impossível. O explorador do satélite, por seu turno, quer que tal comunicação se realize e se realize através do meio por ele colocado à disposição para tal comunicação, o satélite. Por esse serviço, pretende receber uma retribuição, o preço.

Isso é claro na análise funcional dos contratos. O tempo é o elemento primordial do contrato. Não há locação de espaço, mas prestação de tempo do satélite. Se as empresas operadoras deixarem de tornar possível a comunicação por falha técnica de sua responsabilidade, a causa concreta do contrato, o interesse social que o contrato singular pretende perseguir, elas são obrigadas a dar desconto por essas interrupções, tudo a demonstrar que ad breve, nessa interrupção, não haverá causa concreta do contrato.

As empresas operadoras operacionalizam e tornam possível permanentemente a

Revista Quaestio luris, vol.04, no01. ISSN 1516-0351 p.623-654 646 
comunicação de seus clientes. Não querem os clientes dessas empresas operadoras locar nada, nem extrair do bem locado a utilidade que é própria da coisa. Não é o uso e gozo da coisa (os transponders) a causa concreta que dá sentido ao negócio, mas a comunicação. A coisa não é no contrato senão unicamente a ocasião dela (atividade-meio, condição para a prestação do serviço). Se a causa concreta do negócio jurídico é a comunicação e esta só pode ser realizada em função da atividade dessas empresas operadoras por meio do seus satélites no interesse dos seus clientes o contrato em tela não pode deixar de ser qualificado como um contrato de prestação de serviços de comunicação.

3. A qualificação dos contratos das empresas que têm como atividade a cessão de capacidade espacial de satélites como prestação de serviços

Como se depreende de tudo que foi examinado até agora as empresas que têm como atividade a cessão de capacidade espacial de satélites atuam de maneira abragente assumindo toda a direção do processo de transmissão de sinais. Nos contratos em referência a obrigação dessas empresas operadoras transcendem em muito a de um mero cedente ou locador. Se se detivesse a atividade diuturna dessas empresas, toda a utilidade do negócio jurídico entabulado pelas partes desapareceria, e o tomador de serviço só poderia obter proveito do que até então houvesse sido executado. Trata-se aqui, induvidosamente, de prestação de serviço como o fim do contrato porque não se pode conceber a execução dos contratos celebrados entre essas empresas e seus clientes e a atribuição da utilidade ao tomador de serviço (os clientes) nem, por conseguinte, a consecução dos fins que este se havia proposto (a comunicação), sem a contínua colaboração do prestador de serviço (as empresas operadoras), que, com seu próprio esforço tem que produzir as vantagens prometidas. A dita coisa do contrato (a atribuição de órbita e de freqüências) nada é sem a atividade diuturna, prestada em regime integral, 24 (vinte e quatro) horas por dia, todos os dias do mês, das empresas operadoras.

A finalidade prático-social do contrato é a comunicação. As partes do contrato 
querem possibilitar a comunicação. O contratante, o tomador do serviço quer, por exemplo, a transmissão de uma partida de futebol jogada no exterior, por uma estação de TV. Sem o satélite, tal desiderato é impossível. O operador do satélite, por seu turno, quer que tal comunicação se realize e se realize através do meio por ele colocado à disposição para tal comunicação, o satélite. Por esse serviço, pretende receber uma retribuição, o preço. Essa é a base objetiva do negócio firmado entre as partes.

Não pode o uso e gozo da coisa, o transponder, constituir a base objetiva do presente negócio jurídico porque a locação propriamente dita é um negócio jurídico autônomo, pelo qual o locador entrega a coisa locada para que o locatário lhe dê a utilização que lhe é própria, utilizando e gozando da coisa, sem qualquer condicionamento ou vinculação a outro tipo de negócio. Este é o fim contratual do negócio jurídico de locação. Na locação de um veículo, por exemplo, o locador o utiliza sem que haja outro negócio paralelo ou outra remuneração a ser paga, senão o preço do aluguel. Os clientes das empresas operadoras não têm qualquer conhecimento técnico necessário à operação do satélite, nem se propõem a fazê-lo, por iniciativa própria, como se daria em uma locação.

A base do negócio jurídico avençado, sua finalidade prático-social, não pode ser outra senão a comunicação pretendida pelas partes, com transmissão dos sinais feita através do satélite, dirigido e operado com exclusividade pelas empresas operadoras. Então, deste modo, a atividade primordial dessas empresas, é possibilitar essa comunicação e, assim, seu negócio precípuo é a prestação de serviços de comunicação, sendo a parcela por ela denominada de locação, parte incindível da prestação do serviço de comunicação.

É de sabença, por outro lado, que a causa concreta, o interesse prático-social almejado e executado pelas partes, é o determinante na qualificação de um contrato, quando em um mesmo contrato misto, se defrontam as obrigações decorrentes dos tipos contratuais da locação e da prestação de serviços.

A causa concreta do contrato de provimento de capacidade espacial, o interesse 
social que o contrato singular pretende perseguir, é a comunicação. As partes do contrato querem possibilitar a comunicação. O tempo é o elemento primordial do contrato. Não há locação de espaço, mas prestação de tempo do satélite. Se essas empresas operadoras deixarem de tornar possível a comunicação por falha técnica de sua responsabilidade, a causa concreta do contrato, ela é obrigada a dar desconto por essas interrupções, tudo a demonstrar que ad breve, nessa interrupção, não haverá causa concreta do contrato.

Na Europa o mesmo problema da qualificação contratual do chamado provimento de capacidade satelital vem sendo discutido. A Organização para a Cooperação e Desenvolvimento Econômico (Organisation for Economic Co-operation and Development OECD), organização internacional que congrega trinta e um países europeus e não-europeus de economias de mais alta renda e com alto Índice de Desenvolvimento Humano (IDH), elaborou novas mudanças em sua Convenção Modelo em matéria de imposto sobre o rendimento e sobre o patrimônio (Model Tax Convention on Income and on Capital) publicada pela primeira vez em 1992 e, desde, então, atualizada periodicamente.

Em 22 de julho de 2010 a OECD divulgou a $8^{\text {a }}$ edição da versão condensada da Convenção Modelo em matéria de imposto sobre o rendimento e sobre o patrimônio (Model Tax Convention on Income and on Capital) que inclui o texto da Convenção como lido em sessão, após a aprovação da atualização pelo Conselho da OECD.

Nesse texto entabula-se, entre outros assuntos, comentários sobre a correta compreensão do art. 12 da Convenção Modelo que trata da tributação dos royalties provenientes de um Estado contratante e pagas a um residente do outro Estado contratante. Entendidos por royaltes as retribuições de qualquer natureza atribuídas pelo uso ou pela concessão do uso de um direito de autor sobre uma obra literária, artística ou científica, incluindo os filmes cinematográficos, de uma patente, de uma marca de fabrico ou de comércio, de um desenho ou de um modelo, de um plano, de uma fórmula ou de um processo secreto, ou por informações respeitantes a uma experiência adquirida no sector industrial, comercial ou científico: 


\author{
Artigo 12..$^{\circ}$ - Royalties
}

1. Os royalties provenientes de um Estado contratante e pagas a um residente do outro Estado contratante só podem ser tributadas nesse outro Estado.

2. O termo "royalties" usado neste Artigo, significa as retribuições de qualquer natureza atribuídas pelo uso ou pela concessão do uso de um direito de autor sobre uma obra literária, artística ou científica, incluindo os filmes cinematográficos, de uma patente, de uma marca de fabrico ou de comércio, de um desenho ou de um modelo, de um plano, de uma fórmula ou de um processo secreto, ou por informações respeitantes a uma experiência adquirida no sector industrial, comercial ou científico.

3. O disposto no n. ${ }^{\circ} 1$ e 2 não é aplicável se o beneficiário efectivo das royalties, residente de um Estado contratante, exercer actividade no outro Estado contratante de que provêm os royalties, por meio de um estabelecimento estável aí situado, e o direito ou bem relativamente ao qual as royalties são pagas estiver efectivamente ligado com esse estabelecimento estável.

Neste caso, são aplicáveis as disposições do artigo 7.. .

4. Quando, devido a relações especiais existentes entre o devedor e o beneficiário efectivo dos royalties ou entre ambos e qualquer outra pessoa, o montante das royalties, tendo em conta o uso e o direito ou as informações pelas quais são pagas, exceder o montante que seria acordadado entre o devedor e o beneficiário efectivo, na ausência de tais relações, as disposições deste Artigo aplicar-se-ão apenas a este último montante. Neste caso, o excesso pode continuar a ser tributado de acordo com a legislação de cada Estado contratante, tendo em conta as outras disposições desta Convenção.

Ao comentar a tributação dos royalties provenientes de um Estado contratante e pagas

a um residente do outro Estado contratante da Convenção Modelo, o documento da OECD considerou que operadores de satélite e os seus clientes frequentemente firmam acordos de "locação de transponder" pelos quais o operador de satélite permite aos clientes utilizar a capacidade de um transponder de satélite para transmitir seus sinais para grandes áreas geográficas. Aduz todavia a OECD que pagamentos feitos pelos clientes sob esses típicos acordos de "locação de transponder", que são feitos para utilização da capacidade de transmissão do transponder, não constituem royalties na definição do item $n^{\circ} 2$ porque estes pagamentos não são feitos em contrapartida do uso, ou do direito de uso, uma vez que a tecnologia da operação não é transferida para os clientes e estes não tem acesso ao transponder que teria sido atribuído a eles. Nesses casos, assevera a OCDE que os pagamentos feitos pelos clientes teriam, portanto, a natureza de pagamentos por serviços:

9.1 Operadores de satélite e seus clientes (incluindo as empresas de radiodifusão e de telecomunicações) frequentemente realizam "transponder leasing", acordos sob os quais o operador de satélites permite ao cliente utilizar a capacidade de um transponder de satélite para transmitir em grandes áreas geográficas. Pagamentos feitos pelos clientes sob típico acordo de "transponder leasing" são feitos para o uso da capacidade de transmissão de transponder, não constituindo royalties no âmbito da definição do parágrafo $n^{\circ}$. 2: estes pagamentos não são feitos em contrapartida da utilização de, ou direito de uso, propriedade, ou para informação, que é referido para na definição (não podem ser vistos, por exemplo, como pagamentos por informações ou para o uso, ou direito de uso, um

Revista Quaestio luris, vol.04, no01. ISSN 1516-0351 p.623-654 650 
processo secreto uma vez que a tecnologia usada no satélite não é transferida para o cliente). Em relação aos tratados que incluem a locação de equipamentos industriais, comerciais ou científicos (ICS) na definição de royalties, a caracterização do pagamento dependerá, em grande medida, das disposições contratuais pertinentes.

Embora os contratos relevantes, muitas vezes se refiram à "locação" de um transponder, na maioria dos casos o cliente não adquire a posse física do transponder, mas simplesmente sua capacidade de transmissão: o satélite é operado pelo locador e o locatário não tem acesso ao transponder que teria sido atribuído a ele. Nesses casos, os pagamentos feitos pelos clientes teriam, portanto, a natureza de pagamentos por serviços, a que se aplica o artigo 7, ao invés de pagamentos pelo uso, ou pelo direito de uso, de equipamentos ICS. É diferente da muito menos frequente operação, na qual o proprietário do satélite o aluga para outro operador, para que este possa operá-lo e usá-lo para os seus próprios fins ou para oferecer a sua capacidade de transmissão de dados a terceiros. Nesse caso, o pagamento feito pelo operador de satélites para o proprietário de satélite poderia muito bem ser considerado como um pagamento de locação de equipamento industrial, comercial ou científico. Considerações similares se aplicam aos pagamentos efetuados para arrendamento ou compra de capacidade de cabos para a transmissão de energia elétrica ou de comunicação (por exemplo, através de um contrato de concessão de um direito inalienável do uso de tal capacidade) ou condutores (por exemplo, para o transporte de gás ou óleo). 
Do mesmo modo considerou a OECD em seu documento que os pagamentos relativos ao uso, ou ao direito de utilizar, bandas de espectro de radiofrequência (por exemplo, nos termos de uma "licença de espectro" que permite ao seu titular transmitir conteúdo de mídia em faixas de frequências designadas do espectro eletromagnético) não constituem pagamentos por uso ou concessão de direito de uso que é mencionado na definição de royalties do item $\mathrm{n}^{\circ} 2$. Esta conclusão para a OECD é válida mesmo no caso de tratados que incluem a locação de equipamentos industrial, comercial ou científico (ICS) na definição de royalties, uma vez que tal pagamento não é para o uso, ou o direito de uso de qualquer equipamento:

9.2 Além disso, os pagamentos efetuados por um operador de rede de telecomunicações para outro operador de rede em um típico acordo de "roaming" (ver ponto 9.1 do Comentário ao artigo $5^{\circ}$ ) não constituirá royalties no âmbito da definição do parágrafo $\mathrm{n}^{\circ} .2$ uma vez que estes pagamentos não são feitos em consideração do uso, ou direito de uso, de bens ou de informação, referida na definição (não podem ser vistos, por exemplo, como pagamentos pelo uso, ou direito de uso, um processo assim secreto, uma vez que nenhuma tecnologia secreta é usada ou transferida para o operador). Esta conclusão é válida mesmo no caso de tratados que incluem a locação de equipamentos industrial, comercial ou científico (ICS) na definição de royalties uma vez que o operador que paga uma taxa ao abrigo de um acordo de roaming não está pagando pelo uso, ou o direito de usar, a rede visitada, para a qual ele não tem acesso físico, mas sim para os serviços de telecomunicações fornecidos pelo operador de rede externa.

9.3 Pagamentos para o uso de, ou para o direito de usar, algumas ou todas as partes do espectro de frequência de rádio (por exemplo, nos termos de uma chamada "licença de espectro" que permite que o titular transmita conteúdo de mídia em faixas de frequências específicas do espectro eletromagnético) não constituem pagamentos pelo uso de, ou pelo direito de uso, de bens ou de informação, que é referido na definição de royalties no parágrafo $n^{\circ}$. 2. Esta conclusão é válida mesmo no caso de tratados que incluem a locação de equipamentos industrial, comercial ou científico (ICS) na definição de royalties uma vez que o pagamento não é para o uso, ou para o direito de usar, qualquer equipamento.

Por todos esses aspectos, fica plenamente caracterizado que a operação de transmissão de dados constitui, seja por sua natureza, seja por sua conformação fática negocial, estrutural e funcionalmente falando, uma prestação de serviço.

\section{Conclusão}


De tudo o que foi exposto pode-se concluir sucintamente, no que se refere à tributação de ICMS sobre a prestação de serviço de comunicação de cessão de capacidade espacial de satélite:

1. Os contratos firmados pelas empresas que têm como atividade a cessão de capacidade espacial de satélites com seus clientes não configuram contratos de locação. Primeiro porque esses contratos não prevêem a entrega de qualquer coisa aos clientes dessas empresas operadoras. Depois porque o uso e gozo da utilidade proveniente dos contratos para os clientes dessas empresas operadoras não decorre da só natureza da coisa dita cedida, a "capacidade espacial de satélite", e nem pode ser realizado com independência, sem pressupor o esforço contínuo, diuturno e permanente dessas empresas. Em terceiro lugar porque a coisa, o provimento de capacidade espacial, que essas empresas operadoras sustentam entregar não é infungível. Não há poder de direção dos clientes dessas empresas sobre o uso e gozo da coisa dita locada, que permanece o tempo todo sob o mando e controle das empresas operadoras. Não há locação.

2. Os contratos firmados por essas empresas que têm como atividade a cessão de capacidade espacial de satélites classificam-se como contratos de prestação de serviço. Trata-se aqui, induvidosamente, de prestação de serviço porque não se pode conceber a execução dos contratos celebrados entre essas empresas e seus clientes e a atribuição da utilidade ao tomador de serviço (os clientes) nem, por conseguinte, a consecução dos fins que este se havia proposto (a comunicação), sem a contínua colaboração do prestador de serviço (as empresas operadoras), que, com seu próprio esforço, tem que produzir as vantagens prometidas.

3. A base do negócio jurídico avençado, sua finalidade prático-social, não pode ser outra senão a comunicação pretendida pelas partes, com transmissão dos sinais feita através do satélite, dirigido e operado com exclusividade pelas empresas operadoras. Então, deste modo, a atividade primordial dessas empresas operadoras, é possibilitar essa comunicação e, assim, seu negócio precípuo é a prestação de serviços de comunicação, sendo a parcela por ela denominada de locação, parte incindível da prestação do serviço de comunicação. 
4. Por fim, a causa concreta do contrato de provimento de capacidade espacial, o interesse social que o contrato singular pretende perseguir, é a comunicação. As partes do contrato querem possibilitar a comunicação. Isso é claro na análise funcional dos contratos. O tempo é o elemento primordial do contrato. Não há locação de espaço, mas prestação de tempo do satélite. Se essas empresas operadoras deixarem de tornar possível a comunicação por falha técnica de sua responsabilidade, a causa concreta do contrato, elas são obrigadas a dar desconto por essas interrupções, tudo a demonstrar que ad breve, nessa interrupção, não haverá causa concreta do contrato.

5. As empresas que têm como atividade a cessão de capacidade espacial de satélites operacionalizam e tornam possível permanentemente a comunicação de seus clientes. Se a causa concreta do negócio jurídico é a comunicação e esta só pode ser realizada em função das atividades dessas empresas operadoras por meio do seus satélites no interesse dos seus clientes o contrato em tela não pode deixar de ser qualificado como um contrato de prestação de serviços e a natureza da obrigação assumida é a prestação de atividade em interesse de outrem, ou seja, prestação de serviço de comunicação.

6. Portanto, em conclusão, consoante tudo o que foi examinado, não há assim, como se negar, que aquilo que essas empresas operadoras querem apresentar no momento da tributação como locação, nada mais é do que, intrinsecamente, um serviço de comunicação que é prestado pelas empresas operadoras aos seus clientes através de seus satélites. Sendo assim uma prestação de serviço de comunicação é inequívoca a incidência de ICMS sobre a prestação de serviço de comunicação de cessão de capacidade espacial de satélite. 